\title{
Tratamento térmico do amido de batata-doce (Ipomoea batatas $L$.) sob baixa umidade em micro-ondas
}

\author{
Heat moisture treatment of sweet potato starch (Ipomoea batatas L.) in microwave oven
}

Maria Flávia Vaz GONÇALVES ${ }^{1}$, Silene Bruder Silveira SARMENTO ${ }^{1 *}$, Carlos Tadeu dos Santos DIAS ${ }^{2}$, Natália MARQUEZINI ${ }^{1}$

\begin{abstract}
Resumo
O objetivo deste trabalho foi avaliar o efeito do tratamento térmico sob baixa umidade (TTBU) aplicado por forno micro-ondas sobre as propriedades estruturais e funcionais do amido de batata-doce e compará-las com as propriedades de amido tratado pelo método convencional. $\mathrm{O}$ amido extraído dessa raiz foi submetido à modificação física, nas umidades de 25 e $35 \%$, em forno convencional ( $90^{\circ} \mathrm{C} / 16$ horas) e em microondas (35 a $90^{\circ} \mathrm{C} / 1$ hora). O tratamento térmico sob baixa umidade resultou em alterações significativas no teor de amilose e em características como a cristalinidade, suscetibilidade enzimática, fator de expansão e propriedades de pasta. Tais variações evidenciam modificações na estrutura granular interna dos amidos, tanto em áreas cristalinas como amorfas do grânulo. As alterações conferidas pelo TTBU foram variáveis com o tipo de tratamento térmico e com o teor de umidade. A umidade das amostras também foi determinante na modificação da maioria das características do amido, como maior digestibilidade enzimática e redução da expansão, menores picos de viscosidade e quebras de viscosidade, independentemente do tipo de tratamento térmico aplicado. Considerando-se o tipo e a intensidade da modificação física do amido tratado pelo método convencional como referência, a utilização da energia de micro-ondas para esse mesmo fim precisa ser melhor estudada.
\end{abstract}

Palavras-chave: modificação física; tratamento térmico sob baixa umidade; micro-ondas; amido de batata-doce.

\begin{abstract}
The objective of this work was to evaluate the effect of the heat moisture treatment (HMT) applied by microwave on the functional and structural properties of the sweet potato starch and compare them to the properties of the starch treated by the conventional method. The starch extracted from sweet potato root was submitted to physical modification, moisture from 25 to $35 \%$, in a conventional oven $\left(90{ }^{\circ} \mathrm{C} / 16\right.$ hours $)$ and in a microwave oven $\left(35\right.$ to $90^{\circ} \mathrm{C} / 1$ hour). The heat treatment resulted in significant alterations in the amylose content and in characteristics such as crystallinity, enzymatic susceptibility, swelling factor, and paste properties. Such variations evidence modifications in the internal granular structure not only in the crystalline areas, but also in amorphous areas. The alterations induced by HMT varied according to the type of heat treatment and moisture content. The samples' moisture was essential for the alteration of some characteristics of the starch such as the enzymatic digestibility and swelling reduction independent of the type of heat treatment applied. Considering the type and the intensity of the physical modifications of the starch treated by the conventional method as reference, it can be said that the use of microwave the energy for this purpose should be further investigated.
\end{abstract}

Keywords: physical modification; heat moisture treatment; microwave; starch sweet potato.

\section{Introdução}

O amido é o principal carboidrato de reserva produzido pelas plantas e consumido pelo homem. O fato de ser armazenado em grânulos insolúveis em água e de ser facilmente extraível torna-o único na natureza, com ampla possibilidade de utilização diretamente na dieta humana ou na indústria alimentícia (CORDENUNSI, 2006).

As modernas indústrias de alimentos, o desenvolvimento de novos produtos e a necessidade de controle rigoroso da qualidade dos alimentos requerem amidos com propriedades funcionais específicas e que sejam capazes de resistir às condições adversas do processamento. Assim, os amidos regulares podem ser modificados, visando adquirir maior estabilidade, melhoria das características reológicas das pastas, da textura dos géis e da retenção de água, entre outros.

Mais recentemente têm sido encontrados na literatura estudos sobre métodos físicos diferenciados, visando ampliar os tipos ou intensidade de modificação do amido como a radiação UV, plasma, pressão hidrostática e radiação micro-ondas. A aplicação de micro-ondas no processamento de alimentos, de um modo geral, tem crescido devido ao fato desta energia ser considerada mais eficiente que a do processo de aquecimento convencional (ALTON, 1998). Outras vantagens incluem a

Recebido para publicação em 19/7/2007

Aceito para publicação em 19/4/2008 (002695)

${ }^{1}$ Departamento de Agroindústria, Alimentos e Nutrição, Escola Superior de Agricultura Luiz de Queiroz - ESALQ, Universidade de São Paulo - USP, Rua A. Pádua Dias, 11 , CEP 13418-900, Piracicaba - SP, Brasil, E-mail: sbssarme@esalq.usp.br

2 Departamento de Ciências Exatas, Escola Superior de Agricultura Luiz de Queiroz - ESALQ, Universidade de São Paulo - USP, Rua A. Pádua Dias, 11, CEP 13418-900, Piracicaba - SP, Brasil

${ }^{*}$ A quem a correspondência deve ser enviada 
economia de espaço e a eficiência da energia, uma vez que a maior parte da energia eletromagnética é convertida em calor (MERMELSTEIN, 1997).

O TTBU é um processo no qual o amido sob baixos teores de umidade (insuficiente para haver gelatinização) é submetido a temperaturas superiores àquelas de gelatinização. $\mathrm{O}$ tratamento induz modificações estruturais nos grânulos, com consequente alteração de propriedades como a digestibilidade enzimática, poder de inchamento, teor de amilose e propriedades de pasta.

A intensidade de modificação pelo TTBU varia com a origem botânica do amido, sendo mais efetivo no de tuberosas que no de leguminosas e cereais (JACOBS; DELCOUR, 1998). Como existem matérias-primas amiláceas tropicais pouco exploradas industrialmente, a extração e modificação dos amidos destas são de interesse.

O método clássico de aplicar o TTBU consiste em tratar os amidos em fornos a ar ou cozedores sob pressão por tempos prolongados (próximos de 16 horas). Mais recentemente foram propostas melhorias para o TTBU, visando evitar um dos problemas mais frequentes, que é a produção de uma mistura de amido gelatinizado e não gelatinizado (HAGIWARA et al., 1992) e também satisfazer requerimentos práticos para aplicação em escala industrial.

Assim, o objetivo deste trabalho foi aplicar o tratamento térmico ao amido de batata-doce sob condições de baixa umidade por micro-ondas e avaliar o seu efeito sobre as propriedades estruturais e funcionais.

\section{Material e métodos}

\subsection{Material}

A batata-doce (Ipomoea batatas L.) selecionada foi a de polpa branca, cultivar CNPH 792-3, cultivada no município de Presidente Prudente, SP.

A enzima utilizada na avaliação da suscetibilidade à ação enzimática dos amidos foi a alfa amilase pancreática de suíno, tipo VI-B, da SIGMA (A 3176). Na determinação do teor de amilose foi utilizado o Kit amilose/amilopectina, da Megazyme International Ireland.

\subsection{Métodos}

\section{Tratamento térmico do amido}

O procedimento de extração do amido visou técnica com um mínimo de danos à estrutura física do amido. A extração foi efetuada de acordo com Sarmento, 1997.

O amido foi submetido a tratamento de calor sob baixa umidade utilizando-se forno micro-ondas e estufa com circulação e renovação de ar. $\mathrm{O}$ amido foi colocado em placas de Petri, sendo ajustadas as umidades ( 25 e 35\% de umidade) com o auxílio de conta-gotas e homogeneizadas com bastão de vidro. As placas foram tampadas e seladas com fita adesiva e armazenadas sob refrigeração $\left(5^{\circ} \mathrm{C}\right)$ por uma noite para assegurar a homogeneização da umidade das amostras.
O tratamento em forno convencional ocorreu em estufa com circulação e renovação de ar (marca Marconi, mod. 035), na temperatura fixa de $90{ }^{\circ} \mathrm{C}$ e tempo de 16 horas. O tratamento por micro-ondas foi realizado segundo Stevenson, Biswas e Inglett (2005), em forno de micro-ondas analítico (marca ETHOS 1600, Milestone Inc.), que apresenta controle de variáveis como pressão, potência, tempo e temperatura, utilizando carrossel para 10 tubos de teflon, sendo um para o piloto e nove para as amostras. Os tubos fechados foram submetidos ao tratamento térmico pelo tempo de 1 hora, utilizando-se a potência fixa de $0,5 \mathrm{~W} \cdot \mathrm{g}^{-1}$. A temperatura no interior dos tubos foi avaliada por termopares no tubo piloto e nas condições de potência fixa, evoluiu de $35^{\circ} \mathrm{C}$ para $92^{\circ} \mathrm{C}$, conforme o tempo de processamento.

Após o TTBU, as amostras do micro-ondas e do forno convencional foram lavadas duas vezes com etanol absoluto, filtradas em papel de filtro Whatman $n^{\circ} 4$ e desidratadas a $40{ }^{\circ} \mathrm{C}$ em estufa com circulação de ar (Marconi, mod. MA 035) por uma noite.

\section{Teor de amilose}

O teor de amilose foi determinado de acordo com a metodologia proposta pela Megazyme (AMYLOSE/AMYLOPECTIN , 2006), utilizando-se o Kit amilose/amilopectina.

\section{Microscopia eletrônica de varredura}

$\mathrm{O}$ aspecto geral dos grânulos foi observado ao microscópio eletrônico de varredura (MEV), marca ZEISS DSM 940 A, sob amperagem de $80 \mathrm{~mA}$ e voltagem de $5 \mathrm{Kv}$. A montagem das amostras foi feita em suportes (stubs) com fita adesiva dupla face, onde os amidos foram fixados e cobertos com uma fina camada de ouro em metalizador Balzers (Med 010) por 3 minutos.

\section{Difração de raio $X$ dos grânulos}

Após pernoitar em câmara saturada com água, as amostras de amido foram compactadas em suportes específicos e submetidas a um difrator de raios X (marca Philips, mod. X'Pert) para avaliação da cristalinidade dos grânulos. As análises foram feitas segundo Gunaratne, Hoover, 2002, utilizando velocidade de varredura de $2 \%$ minuto e condições de trabalho de $40 \mathrm{kv}$ e $20 \mathrm{~mA}$. Os perfis de difração dos raios X foram classificados de acordo com os padrões de Zobel, 1964.

\section{Digestibilidade enzimática}

A análise da digestibilidade enzimática do amido foi baseada em Zhang e Hamaker, 1998 e Benmoussa et al., 2006, com algumas modificações. A uma amostra de amido (200 mg) foram adicionados $5 \mathrm{~mL}$ de água. Após 20 minutos em banho-maria fervente o material foi resfriado a $40^{\circ} \mathrm{C}$. Uma solução $(25 \mathrm{~mL})$ da enzima $\alpha$-amilase pancreática de suíno em tampão glicerolfosfato de sódio $\mathrm{pH}$ 6,9 ( $1 \mathrm{mM}$ glicerolfosfato de sódio, $25 \mathrm{mM} \mathrm{NaCl}$ e $5 \mathrm{mM} \mathrm{CaCl}_{2}$ ) na proporção 5 unidades $/ \mathrm{mL}$ foi adicionada ao amido gelatinizado. A suspensão foi incubada a $37^{\circ} \mathrm{C}$ e a intervalos de tempo $(10,20$, 40, 60, 90 e 120 minutos) foi retirada uma alíquota de $1 \mathrm{~mL}$. A reação foi paralisada em banho-maria fervente por 10 minutos 
e, em seguida, a concentração de açúcar redutor foi determinada utilizando-se o método Somogy, 1945.

Fator de expansão dos grânulos

Para a determinação do fator de expansão nas temperaturas de $50,60,70,80$ e $90^{\circ} \mathrm{C}$ foi utilizado o método direto proposto por Tester e Morrison, 1990.

\section{Propriedades das pastas de amidos}

As propriedades de pasta foram avaliadas em aparelho Rapid Visco Analyser (RVA), série S4A (RVA Super 4), da Newport Scientific, na concentração de 2,5 g/25 mL de água. Foi utilizada a programação Standard Analysis 2, do software Thermocline for Windows, versão 3.0.

\section{Análise estatística}

No delineamento experimental foram utilizados 2 lotes distintos com 2 repetições. Foram testados dois equipamentos para a realização do TTBU e dois teores de umidade das amostras. As análises de variância (ANOVA) e o teste de Tukey $(\mathrm{p}<0,05)$ foram realizados usando-se o sistema SAS versão 9.1 (SAS, 2002/2003).

\section{Resultados e discussão}

\subsection{Teor de amilose}

O teor de amilose no amido de batata-doce natural (Tabela 1) foi próximo aos teores encontrados por Collado e Corke, 1999; Noda; Takahata e Nagata, 1992; Noda et al., 1998, que foram respectivamente: 19,1 e 20,2 e 19,7\%. Entretanto, Vieira, 2004; Peroni, 2003 e Hoover, 2001, reportaram teores mais elevados de amilose em amido da mesma fonte botânica: 22,2 e 25,6 e $27,0 \%$, respectivamente.

$\mathrm{O}$ amido de batata-doce tratado no forno convencional, em ambas as umidades, apresentou teores de amilose significativamente maiores que o apresentado pelo amido nativo (natural), entretanto, os tratados por micro-ondas não tiveram tais alterações. Este fato mostra que o tipo de aplicação de calor pode influenciar o(s) parâmetro(s) responsável(responsáveis) pelo aumento ou não dos teores desta macromolécula e que, dentro do mesmo tipo de aquecimento, a umidade das amostras não interferiu neste comportamento.

A elevação do teor de amilose nos amidos de batata e milho por efeito do tratamento térmico $\left(110^{\circ} \mathrm{C} / 30\right.$ minutos em umidade saturada, $125^{\circ} \mathrm{C} / 20$ minutos e $125^{\circ} \mathrm{C} / 20$ minutos após vácuo) foi também observada por Miyoshi, 2002. O autor sugeriu que esse aumento decorre da degradação das cadeias lineares mais externas da amilopectina, se tornando cadeias de amilose, que podem ser complexadas por outras cadeias de amilose ou lipídios, indicando a formação de novas regiões cristalinas, com diferentes estabilidades térmicas dentro das regiões amorfas.

\subsection{Microscopia eletrônica de varredura}

A aparência dos grânulos do amido de batata-doce (Figura 1) foi típica desta fonte de amido, com formatos redondos, ovalados e poligonais, os mesmos relatados por Cereda et al., 2001, Katayama et al., 2002, Hoover, 2001 e Matsuguma, 2006.

As superfícies dos grânulos apresentaram-se lisas e sem evidências de quebras, rachaduras após os tratamentos por TTBU. Alguns trabalhos da literatura também não observaram alterações em amidos de milho normal, ceroso e de alto teor de amilose tratados por TTBU $\left(100{ }^{\circ} \mathrm{C} / 16\right.$ horas) com $30 \%$ de umidade (HOOVER; MANUEL, 1996). Outros autores observaram haver pequenas alterações nos amidos de arroz ceroso tratados em micro-ondas, ficando com os grânulos mais aglomerados que o natural, porém a morfologia do grânulo não foi alterada (ANDERSON; GURAYA, 2005). No presente trabalho o amido quando tratado por micro-ondas a 35\% de umidade apresentou tendência a formar mais aglomerados.

\subsection{Difração de raio X dos grânulos}

O tratamento por TTBU promoveu modificações perceptíveis nos perfis de difração de raio $\mathrm{X}$ do amido de batata-doce em relação à curva do amido original (Figura 2). As alterações foram mais acentuadas ou menos, conforme o tratamento. Os amidos tratados por micro-ondas, principalmente em umidade de $25 \%$, apresentaram-se mais modificados que os tratados pelo forno convencional. Os picos apresentaram-se nos mesmos espaços interplanares, mas com intensidades e formatos que evidenciam rearranjos das regiões cristalinas/amorfas dos grânulos.

$\mathrm{O}$ amido apresentou o padrão de cristalinidade do tipo $\mathrm{C}_{\mathrm{B}}$, ou seja, C com proximidade ao B. Resultado semelhante foi encontrado por Shin et al., 2005. Já Hizukuri, 1996 e Zobel, 1998, encontraram o padrão do tipo C.

As alterações nos picos não foram suficientes para modificar o padrão de cristalinidade estabelecido para o amido nativo $\left(\mathrm{C}_{\mathrm{B}}\right)$, entretanto, tornaram a definição do padrão mais difícil.

\subsection{Digestibilidade enzimática}

A suscetibilidade do amido pela alfa-amilase de pâncreas suíno aumentou após o TTBU (Tabela 2), mostrando haver rompimentos e rearranjos cristalinos que facilitaram o ataque da enzima.

Tabela 1. Teores médios de amilose (\%) dos amidos de batata-doce natural e tratados por TTBU.

\begin{tabular}{lcccc}
\hline Natural & Forno convencional 25\% & Forno convencional 35\% & Forno micro-ondas 25\% & Forno micro-ondas 35\% \\
\hline Amilose $19,19 \pm 0,6^{1 \mathrm{~b} 2}$ & $21,97 \pm 2,0^{\mathrm{a}}$ & $24,38 \pm 1,0^{\mathrm{a}}$ & $17,20 \pm 1,8^{\mathrm{b}}$ & $17,92 \pm 0,1^{\mathrm{b}}$ \\
\hline $\begin{array}{l}{ }^{1} \text { Média } \pm \text { Desvio Padrão. } \\
{ }^{2} \text { Médias seguidas da mesma letra na linha não diferem entre si pelo Teste de Tukey, em nível de 5\% de probabilidade. }\end{array}$
\end{tabular}



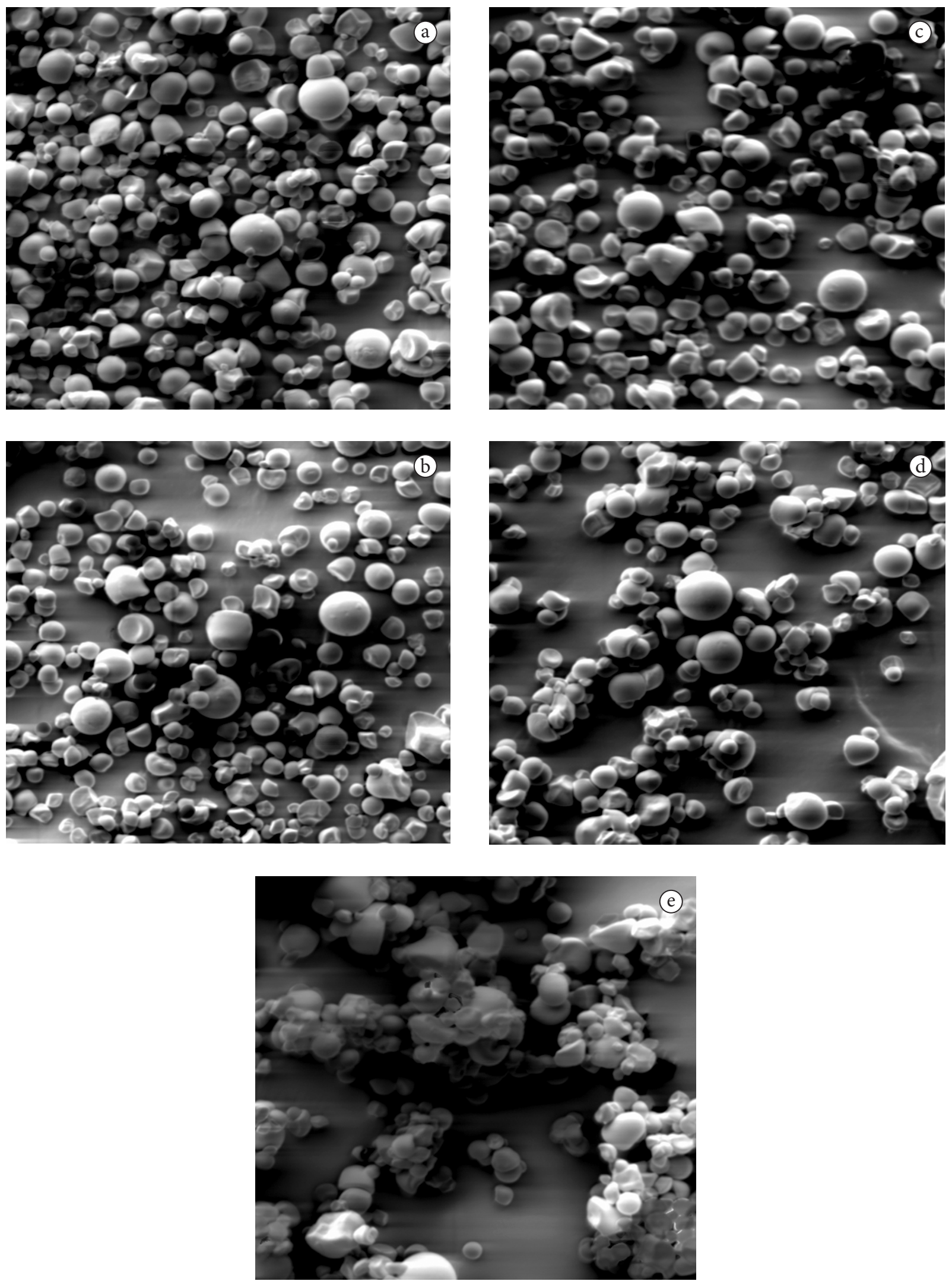

Figura 1. Fotomicrografias do amido de batata-doce em microscópio eletrônico de varredura. a) natural b) TTBU em forno convencional com $25 \%$ de umidade; c) TTBU em forno convencional com 35\% de umidade; d) TTBU em forno micro-ondas com 25\% de umidade; e) TTBU em forno micro-ondas com $35 \%$ de umidade. 
O menor aumento foi observado no amido tratado por micro-ondas a $25 \%$ de umidade, cuja suscetibilidade aproximou-se mais do natural. O tratamento em forno micro-ondas de um modo geral modificou menos a suscetibilidade enzimática do que o tratado no forno convencional. Foi também evidente a influência da umidade das amostras na alteração da suscetibilidade enzimática deste amido. Sob maior umidade, o amido teve maior aumento da suscetibilidade enzimática.

Hoover e Vasanthan, 1994, Jane, Wang e Mcpherson, 1997, Gunaratne e Hoover, 2002, citam que, dentre outros, fatores como tamanho do grânulo, teor de amilose e cristalinidade podem interferir na digestibilidade enzimática do amido das diversas fontes (cereais e tubérculos).

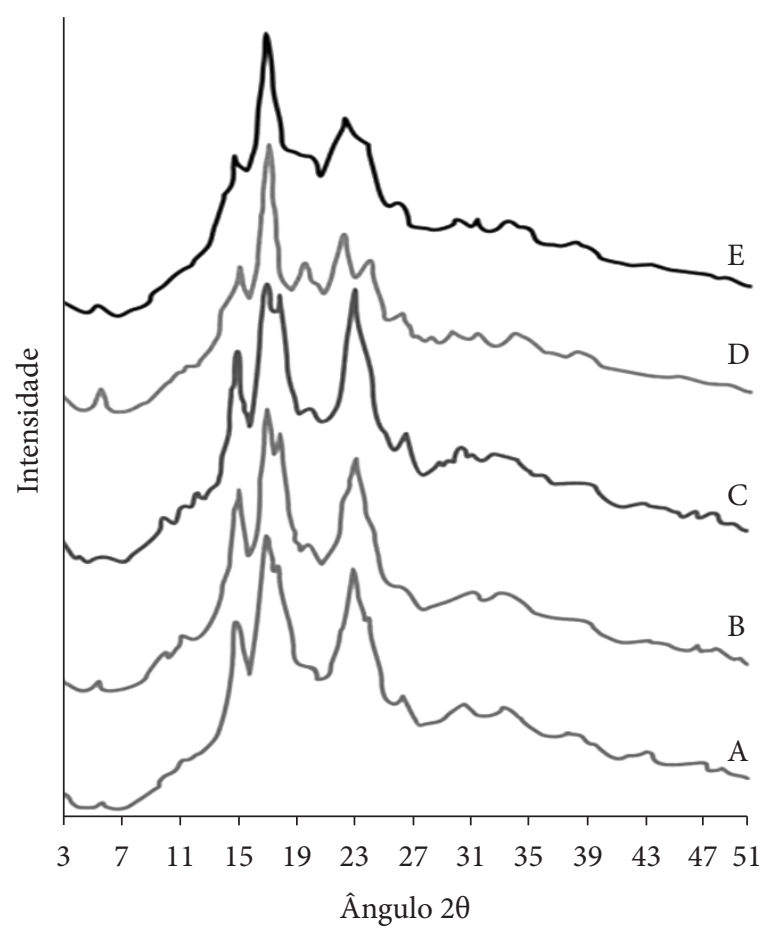

Figura 2. Difratogramas de raio $\mathrm{X}$ do amido de batata-doce natural e tratados por TTBU: a) Natural; b) Forno convencional 25\%; c) Forno convencional 35\%; d) Forno micro-ondas 25\% e e) Forno micro-ondas $35 \%$.
Nas condições do presente estudo, os amidos de batatadoce tratados em forno convencional a 25 e $35 \%$ apresentaram elevação do teor de amilose após serem submetidos ao tratamento térmico. Coincidentemente, este foi o tratamento que apresentou maior suscetibilidade enzimática se comparado com seu amido natural.

Embora o tratamento por micro-ondas tenha modificado mais o difratograma de raio $\mathrm{X}$ do amido que o forno convencional, essa modificação, entretanto, não mostrou correspondência com aquela ocorrida para acessibilidade das enzimas hidrolíticas, que se mostrou maior para o amido tratado no forno convencional. O tratamento convencional deve ter ampliado as áreas de acesso à enzima.

\subsection{Fator de expansão dos grânulos}

O TTBU reduziu o fator de expansão dos grânulos de amido em todos os tratamentos (Figura 3), entretanto, o fator de expansão foi menor (maior redução) para amidos tratados no forno convencional do que no de micro-ondas. A modificação também mostrou ser afetada pela umidade das amostras, quanto maior a umidade, menor a expansão observada. As diferenças entre tratamentos foram se intensificando com o aumento da temperatura do teste de expansão, tornando-se mais evidentes após os $70^{\circ} \mathrm{C}$.

Moorthy, 2002, em estudo sobre as propriedades de amido de diversas raízes tropicais, observou que um dos fatores que interferem no volume de expansão é o conteúdo de amilose (alta quantidade reduz o poder de expansão). No presente estudo houve correspondência entre aumento de teores de amilose e redução do fator de expansão dos grânulos de amido de batata-doce tratado no forno convencional em ambas as umidades.

A maior suscetibilidade à ação enzimática foi evidenciada nos amidos tratados no forno convencional, que, por sua vez, também apresentaram a maior redução do fator de expansão dos grânulos.

\subsection{Propriedades das pastas de amidos}

A Figura 4 mostra que os parâmetros de viscosidade foram alterados pelo TTBU.

Os perfis de viscosidade dos amidos tratados pelo forno convencional foram mais afetados que os tratados no micro-ondas e

Tabela 2. Teores médios de açúcares redutores (mg de açúcar redutor/mL) produzidos durante a digestão enzimática do amido de batata-doce natural e tratados por TTBU em diferentes condições.

\begin{tabular}{rccccc}
\hline & Natural & Forno convencional 25\% & Forno convencional 35\% & Forno micro-ondas 25\% & Forno micro-ondas 35\% \\
\hline 10 & $1,7 \pm 32,6^{1 \mathrm{c} 2}$ & $2,1 \pm 29,4^{\mathrm{b}}$ & $2,7 \pm 53,0^{\mathrm{a}}$ & $0,9 \pm 20,9^{\mathrm{e}}$ & $1,2 \pm 36,0^{\mathrm{d}}$ \\
20 & $1,9 \pm 48,7^{\mathrm{c}}$ & $2,5 \pm 25,0^{\mathrm{b}}$ & $3,2 \pm 20,4^{\mathrm{a}}$ & $1,7 \pm 23,0^{\mathrm{d}}$ & $2,4 \pm 44,9^{\mathrm{b}}$ \\
40 & $2,3 \pm 11,5^{\mathrm{d}}$ & $2,8 \pm 57,1^{\mathrm{b}}$ & $3,5 \pm 24,5^{\mathrm{a}}$ & $2,3 \pm 14,6^{\mathrm{d}}$ & $2,7 \pm 40,4^{\mathrm{c}}$ \\
60 & $2,4 \pm 10,9^{\mathrm{d}}$ & $3,2 \pm 2,7^{\mathrm{b}}$ & $3,8 \pm 20,2^{\mathrm{a}}$ & $2,7 \pm 32,0^{\mathrm{c}, \mathrm{d}}$ & $2,9 \pm 14,5^{\mathrm{b}, \mathrm{c}}$ \\
90 & $3,0 \pm 53,3^{\mathrm{c}}$ & $3,2 \pm 19,0^{\mathrm{b}}$ & $4,3 \pm 26,0^{\mathrm{a}}$ & $3,0 \pm 27,3^{\mathrm{c}}$ & $3,2 \pm 73,4^{\mathrm{b}}$ \\
120 & $3,1 \pm 42,3^{\mathrm{c}}$ & $3,5 \pm 59,8^{\mathrm{b}}$ & $4,3 \pm 61,7^{\mathrm{a}}$ & $3,2 \pm 38,1^{\mathrm{b}, \mathrm{c}}$ & $3,3 \pm 20,7^{\mathrm{b}, \mathrm{c}}$ \\
\hline
\end{tabular}

${ }^{1}$ Média \pm Desvio Padrão.

${ }^{2}$ Médias seguidas da mesma letra na linha não diferem entre si pelo Teste de Tukey, em nível de 5\% de probabilidade. 
Tabela 3. Propriedades de pasta $(2,5 \mathrm{~g} / 25 \mathrm{~mL}$ de água) dos amidos de batata-doce natural e modificados por TTBU.

\begin{tabular}{|c|c|c|c|c|c|c|}
\hline & \multirow[t]{2}{*}{ Temperatura de pasta $\left({ }^{\circ} \mathrm{C}\right)$} & \multirow[t]{2}{*}{ Tempo de pico (min) } & \multicolumn{4}{|c|}{ Viscosidade (RVU) } \\
\hline & & & Máxima & Quebra & Final & Tendência retrogradação \\
\hline Natural & $72,8 \pm 0,9^{1 \mathrm{~d} 2}$ & $7 \pm 0,0^{\mathrm{d}}$ & $270 \pm 10,6^{\mathrm{a}}$ & $131 \pm 6,1^{\mathrm{a}}$ & $211 \pm 4,9^{c}$ & $72 \pm 3,3^{d}$ \\
\hline Forno convencional $25 \%$ & $80,9 \pm 0,7^{\mathrm{b}}$ & $10 \pm 0,4^{\mathrm{b}}$ & $190 \pm 8,6^{c}$ & $4 \pm 3,7^{c}$ & $326 \pm 6,2^{\mathrm{a}}$ & $141 \pm 3,2^{\mathrm{a}}$ \\
\hline Forno microondas $25 \%$ & $75,4 \pm 1,2^{\mathrm{c}}$ & $7 \pm 0,1^{\mathrm{d}}$ & $284 \pm 21,4^{\mathrm{a}}$ & $119 \pm 24,2^{\mathrm{a}}$ & $256 \pm 3,4^{\mathrm{b}}$ & $92 \pm 1,8^{c}$ \\
\hline Forno microondas 35\% & $79,2 \pm 0,9^{b}$ & $9 \pm 0,1^{\mathrm{c}}$ & $235 \pm 10,7^{\mathrm{b}}$ & $33 \pm 5,9^{b}$ & $328 \pm 6,3^{\mathrm{a}}$ & $126 \pm 3,3^{\mathrm{b}}$ \\
\hline
\end{tabular}

${ }^{1}$ Média \pm Desvio Padrão.

${ }^{2}$ Médias seguidas da mesma letra na coluna não diferem entre si pelo Teste de Tukey em nível de 5\% de probabilidade.
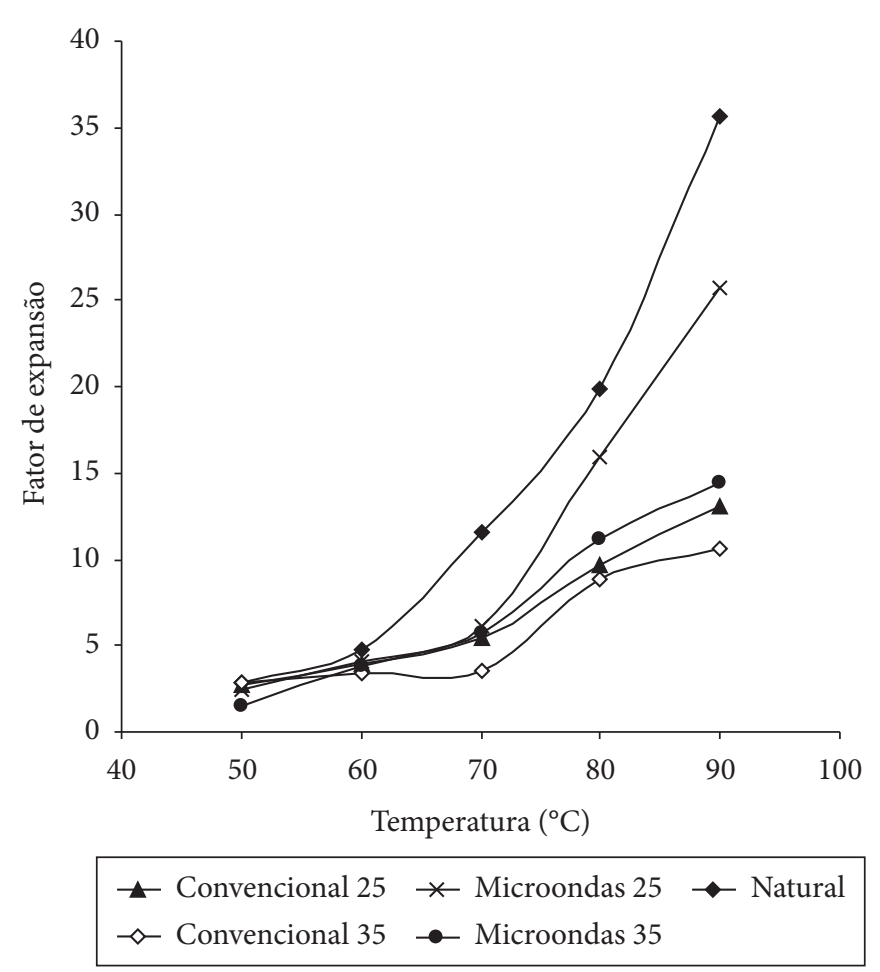

Figura 3. Fator de expansão do amido de batata-doce natural e tratado por TTBU em várias temperaturas.

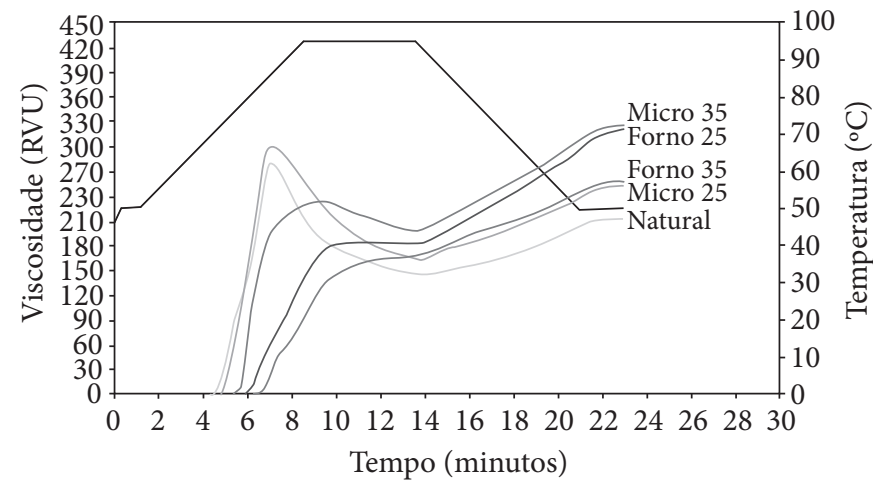

Figura 4. Perfis de viscosidade (RVA) de suspensões $(2,5 \mathrm{~g} / 25 \mathrm{~mL})$ de amidos de batata-doce, natural e modificados por TTBU em forno convencional e em forno micro-ondas. apresentaram perfis mais próximos aos de amidos de cereais, com maior estabilidade a quente sob cisalhamento. Considerando-se o teor de umidade, os tratados com 35\% de umidade sofrem mais o impacto das modificações que aqueles a $25 \%$ de umidade. Essas alterações ficam evidentes pelos dados da Tabela 3.

Os parâmetros aumentados pelo TTBU, exceto pelo microondas a $25 \%$, foram a temperatura de pasta, tempo de pico, viscosidade final e tendência à retrogradação. Entretanto, o pico de viscosidade e a quebra diminuíram após o tratamento dos amidos. No entanto, tais alterações foram variáveis com o tipo de tratamento térmico. As propriedades de pasta do amido tratado em micro-ondas a $25 \%$ foram as menos afetadas pelo TTBU, assemelhando-se àquelas do amido natural. As maiores reduções de quebra (estabilidade frente a altas temperaturas sob cisalhamento) foram observadas no amido de batata-doce tratado em forno convencional a 35\%. A tendência a retrogradação aumentou principalmente para o amido tratado em forno convencional a $25 \%$.

\section{Conclusões}

O tratamento térmico do amido de batata-doce sob baixa umidade reduziu o fator de expansão dos grânulos de amido em todos os tratamentos, com menor expansão para o amido tratado em forno convencional.

As variações observadas em decorrência dos tratamentos térmicos foram na composição macromolecular e estrutura granular interna do amido, nas áreas cristalinas e amorfas do grânulo.

De um modo geral, o forno convencional modificou de forma mais intensa as propriedades dos amidos, proporcionando aumento do teor de amilose, maior redução do fator de expansão dos grânulos e modificações mais acentuadas nos perfis de viscosidade e nas propriedades de pasta.

As umidades mais elevadas promoveram maior digestibilidade enzimática e maior redução da expansão, dos picos de viscosidade e da quebra de viscosidade.

São necessários mais estudos utilizando a energia de micro-ondas para investigar com mais detalhe a modificação do amido. 


\section{Referências bibliográficas}

ALTON, W. J. Microwave pasteurization of liquids. Dearborn: Society of Manufacturing Engineers Paper, 1998. No. EM98-211.

AMYLOSE/AMYLOPECTIN. Wicklow. Ireland: Megazyme International, $2006.8 \mathrm{p}$

ANDERSON, A. K.; GURAYA, H. S. Effects of microwave heat-moisture treatment on properties of waxy and non-waxy rice starches. Food Chemistry, v. 97, n. 2, p. 1-6, 2005.

BENMOUSSA, M. et al. Distinctive sorghum starch granule morphologies appear to improve raw starch digestibility. Starch/Stärke, v. 58, n. 2, p. 92-99, 2006.

CEREDA, M. P (Coord.). Propriedades gerais do amido (Série Culturas de Tuberosas Amiláceas Latino Americanas). Campinas: Fundação Cargill, 2001.

COLLADO, S. L.; CORKE, H. Heat-moisture treatment effects on sweet potato starches differing in amylose content. Food Chemistry, v. 65, n. 3, p. 339-346, 1999.

CORDENUNSI, B. R. Utilização de novas técnicas de microscopia na caracterização do amido. In: LAJOLO, F. M.; MENEZES, E. W. Carbohidratos em alimentos regionales iberoamericano. São Paulo: Edusp, 2006. p. 49-62.

GUNARATNE, A.; HOOVER, R. Effect of heat-moisture treatment on the structure and physicochemical properties of tuber and root starches. Carbohydrate Polymers, v. 49, n. 4, p. 425-437, 2002.

HAGIWARA, S. et al. Physical properties and digestion trial with amylose of heat-moisture treated starch granules. Journal of Japanese Society of Starch Science, v. 39, p. 175-182, 1992.

HIZUKURI, S. Starch: analytical aspects. In: ELIASSON, A. C. (Ed.). Carbohydrates in foods. New York: Marcel Dekker, 1996. p. 347-430.

HOOVER, R. Composition, molecular structure, and physicochemical properties of tuber and root starches: a review. Carbohydrate Polymers, v. 45, n. 3, p. 253-267, 2001.

HOOVER, R.; VASANTHAN, T. Effect of heat moisture treatment on the structure and physicochemical properties of cereal, legume and tuber starches. Carbohydrate Research, v. 252, n. 1, p. 33-53, 1994.

HOOVER, R.; MANUEL, H. The effect of heat moisture treatment on the structure and physicochemical properties of normal maize, waxy maize, dull waxy maize and amylomaize $\mathrm{V}$ starchs. Journal of Cereal Science, v. 23, n. 2, p. 153-162, 1996.

JANE, J. L.; WANG, K. S.; MCPHERSON, A. E. Branch structure difference in starches of A and B-type X-ray pattern revealed by their naegeli dextrins. Carbohydrate Research, v. 300, n. 3, p. 219-227, 1997.

JACOBS, H.; DELCOUR, A. J. H. Hydrotermal modifications of granular starch, with retention of the granular structure: A review. Journal of Agricultural and Food Chemistry, v. 46, n. 8, p. 2895-2905, 1998.

KATAYAMA, K. et al. New sweet potato line having low gelatinization temperature and altered starch structure. Starch/Stärke, v. 54, n. 2, p. 51-57, 2002.

MATSUGUMA, S. L. Caracterização do amido de mandioquinhasalsa (Arracacia xanthorrhiza) nativo e modificado por oxidação. 2006. 100 f. Dissertação (Mestrado em Ciência e Tecnologia de
Alimentos) - Faculdade de Engenharia de Alimentos, Universidade Estadual de Ponta Grossa, Ponta Grossa, 2006.

MERMELSTEIN, N. H. How food technology covered microwaves over the years. Food Technology, v. 51, n. 5, p. 82-84, 1997.

MIYOSHI, E. Effects of heat-moisture treatment and lipids on gelatinization and retrogradation of maize and potato starches. Cereal Chemistry, v. 79, n. 1, p. 72-77, 2002.

MOORTHY, N. S. Physical and functional properties of tropical tuber starches: A review. Starch/Stärke, v. 54, n. 12, p. 559-592, 2002.

NODA, T.; TAKAHATA, Y.; NAGATA, T. Developing changes in properties of sweet potato starches. Starch/Stärke, v. 44, n. 11, p. 405-409, 1992.

NODA, T. et al. Relationships between chain length distribution of amylopectin and gelatinization properties within the same botanical origin for sweet potato and buckwheat. Carbohydrate Polymers, v. 37, n. 2, p. 153-158, 1998.

PERONI, F. H. G. Características estruturais e físico-químicas de amidos obtidos de diferentes fontes botânicas. 2003. 118 f. Dissertação (Mestrado em Engenharia e Ciência de Alimentos) - Instituto de Biociências Letras e Ciências Exatas, Universidade Estadual Paulista "Júlio de Mesquita Filho", São José do Rio Preto, 2003.

SAS INSTITUTE Inc. System for Microsoft Windows. Release 9.1. Cary, NC, USA: 2002/2003

SARMENTO, S. B. S. Caracterização da fécula de mandioca (Marinhot esculenta C.) no período de colheita de cultivares de uso industrial. 1997. 126 f. Tese (Doutorado) - Departamento de Alimentos e Nutrição Experimental, Faculdade de Ciências Farmacêuticas, Universidade de São Paulo, São Paulo.

SHIN, I. et al. Effect of hydrothermal treatment on formation and structural characteristics of slowly digestible non-pasted granular sweet potato starch. Starch/Stärke, v. 57, n. 9, p. 421-430, 2005.

SOMOGY, M. Determination of blood sugar. Journal of Biological Chemistry, v. 160, n. 1, p. 69-73, 1945.

STEVENSON, D. G.; BISWAS, A.; INGLETT, G. E. Thermal and pasting properties of microwaved corn starch. Starch/ Stärke, v. 57, n. 8, p. 347-353, 2005.

TESTER, F. R.; MORRISON, W. R. Swelling and gelatinization of cereal starches.I. effects of amylopectin, amylose, and lipids. American Association of Cereal Chemistry, v. 67, n. 6, p. 551-557, 1990.

VIEIRA, F. C. Efeito do tratamento com calor e baixa umidade sobre características físicas e funcionais dos amidos de mandioquinha-salsa (Arracacia xanthorrhiza), de batata-doce (Ipomoea batatas) e de gengibre (Zingiber officinale). 2004. 103 f. Dissertação (Mestrado em Ciência e Tecnologia de Alimentos) - Escola Superior de Agricultura "Luiz de Queiroz", Universidade de São Paulo, Piracicaba.

ZHANG, G.; HAMAKER, B. R. Low $\alpha$-amylase starch digestibility of cooked sorghum flours and the effect of protein. Cereal Chemistry, v. 75, n. 5, p. 710-713, 1998.

ZOBEL, H. F. X-ray analysis of starch granules In: WHISTLER, R. L. (Ed.). Methods in carbohydrates chemistry. New York: Academic Press, 1964. p. 1.

ZOBEL, H. F. Molecules to granules: A comprehensive starch review. Starch/Stärke, v. 40, n. 2, p. 44-50, 1988. 